\title{
Controle Químico de Fusarium moniliforme em Sementes de Milho: Metodologia de Avaliação e Efeitos sobre a Qualidade Fisiológica
}

\author{
Maria H. D. Moraes, José O. M. Menten, Jouse C. Gravena \& Camila A. Alves \\ Departamento de Entomologia, Fitopatologia e Zoologia Agrícola, Escola Superior de Agricultura "Luiz de Queiroz", \\ Universidade do Estado de São Paulo, Cx. Postal 09, CEP 13418-900, Piracicaba, SP, fax: (19) 3434-4839, e-mail: \\ mhdmorae@carpa.ciagri.usp.br
}

(Aceito para publicação em 27/06/2003)

Autor para correspondência: Maria Heloisa D. Moraes

MORAES, M.H.D., MENTEN, J.O.M., GRAVENA, J.C. \& ALVES, C.A. Controle químico de Fusarium moniliforme em sementes de milho: metodologia de avaliação e efeitos sobre a qualidade fisiológica. Fitopatologia Brasileira 28:626-632. 2003.

\section{RESUMO}

Objetivou-se verificar o efeito da luz sobre o crescimento micelial de Fusarium moniliforme em meio de cultura contendo fungicidas, o melhor regime luminoso e a variável a ser utilizada para detectar o patógeno em sementes tratadas de milho (Zea mays), e o efeito do tratamento sobre a qualidade sanitária e fisiológica das sementes. Os fungicidas avaliados foram fludioxonil + metalaxil-m (três concentrações), difenoconazole, acibenzolar-S-metílico e captan + tiabendazole. Para avaliação do crescimento micelial, os fungicidas foram adicionados em meio de cultura, nas concentrações de 100, 10 e $1 \mathrm{~g} / \mathrm{ml}$. Incubaram-se as placas sob temperatura de $20 \pm 2{ }^{\circ} \mathrm{C}$ e três condições de luz: escuro contínuo, luz branca e luz próxima da ultra violeta ( $12 \mathrm{~h}$ de luz/12 de escuro). Para verificar o efeito da luz na avaliação das sementes tratadas, utilizou-se o método do papel de filtro com congelamento; a sanidade foi avaliada pelas variáveis incidência e severidade. Duas amostras de sementes tratadas foram submetidas aos testes de sanidade, germinação, emergência em casa de vegetação e frio, para verificar o efeito do tratamento sobre a qualidade sanitária e fisiológica. O teste in vitro indicou que a luz branca diminuiu o efeito dos ingredientes ativos fludioxonil + metalaxil-m $(7,5 \mathrm{~g}+11,51 \mathrm{~g} / \mathrm{l}$ e $25 \mathrm{~g}+10 \mathrm{~g} / \mathrm{l})$ e captan + tiabendazole; no teste de sanidade não se observou esse efeito. A severidade foi mais sensível para discriminar a eficiência dos fungicidas. Os resultados obtidos, avaliando-se as amostras de sementes tratadas, demonstraram que: F. moniliforme não afeta a qualidade fisiológica dessas sementes; o fungicida que ofereceu controle do patógeno na semente, acima de $90 \%$, foi captan + tiabendazole, seguido de fludioxonil + metalaxil-m $(97,2 \mathrm{~g}+147,86 \mathrm{~g} / \mathrm{l}) ;$ Pythium $\mathrm{sp}$. foi controlado por captan + tiabendazole e por fludioxonil + metalaxilm nas três concentrações.

Palavras-chave adicionais: fungicidas, luz, germinação, vigor.

\section{ABSTRACT}

Chemical control of Fusarium moniliforme in corn seeds: methodology of evaluation and effects on the physiological quality

The objectives of this study were to evaluate the effect of light regimes on the mycelial growth of Fusarium moniliforme in fungicide-amended culture medium; to select the best light regime to detect $F$. moniliforme in treated corn (Zea mays) seeds and the variable to be used; and the effect of treatment on seed health and physiological quality. The fungicides evaluated were: fludioxonil + metalaxyl-m (three concentrations), difenoconazole, acibenzolar-S-methyl e captan + thiabendazole. For evaluation of mycelial growth, fungicides were added to the culture medium at three concentrations $(100,10$ and 11 $(\mathrm{g} / \mathrm{ml})$. Inoculated plates were incubated at $20 \pm 2{ }^{\circ} \mathrm{C}$, under three light conditions: total darkness, white light and near ultraviolet light (12 h of light/12 $\mathrm{h}$ of darkness). In order to evaluate the effect of light on fungicide-treated seeds, a deep freezing test was carried out and seeds were incubated under the same conditions as the former test; seed health test was evaluated by measuring disease incidence and severity. Two seed samples were treated and submitted to seed health, germination, seedling emergence rates in greenhouse and cold tests. In vitro tests indicated that white light decreased the effect of the active ingredients fludioxonil + metalaxyl-m and captan + thiabendazole. The health test did not show this effect. Severity of the disease was found to be the most sensitive variable to distinct efficacy of fungicides in controlling $F$. moniliforme in corn seeds. The results found for both the two seeds samples suggested that: a) Fusarium moniliforme does not affect the physiological quality of corn seeds; $b$ ) the fungicide that controlled the pathogen in seeds was captan + thiabendazole, followed by fludioxonil + metalaxyl-m $(97.2 \mathrm{~g}+147.86$ g/l); c) Pythium sp. was controlled by captan + thiabendazole and by fludioxonil + metalaxyl-m at the three concentrations.

\section{INTRODUÇÃO}

O fungo Fusarium moniliforme Sheld. é um dos patógenos que causam podridão do colmo e da espiga de milho (Zea mays L.), acarretando queda na produtividade da cultura (Pereira, 1995). O patógeno pode ser transportado pelas sementes e as consequiências desse transporte podem ser a introdução em áreas isentas, o aumento do inóculo na área e a redução da qualidade fisiológica das sementes (Machado, 1988; Menten, 1991a).

Existem trabalhos controversos quando se trata do efeito de $F$. moniliforme sobre a qualidade fisiológica das sementes de milho. Vários autores constataram que não afeta a germinação das sementes (Bedendo, 1978; Pinto et al., 1992; 
Pinto, 1993; Pinto, 1996), enquanto Tanaka \& Balmer (1980) observaram tombamento causado pelo patógeno, sob condições adversas de germinação. Futrell \& Kilgoore (1969) e Bacon et al. (1994) afirmam, também, que F. moniliforme pode inibir o desenvolvimento da raiz de plântulas de milho. Carvalho et al. (1992) constataram redução na germinação de sementes de milho com infecção por $F$. moniliforme.

Uma das maneiras mais eficientes de reduzir os danos causados pela associação desse fungo com as sementes é o tratamento químico das mesmas. Vários fungicidas têm sido comparados para se verificar seu efeito no controle dos fungos presentes nas sementes de milho e no desempenho destas em laboratório e campo. Um dos fungicidas utilizados é o fludioxonil + metaxil que, segundo Goulart \& Fialho (2001), proporcionou acréscimo de $56 \%$ no rendimento de grãos. Porém, nem sempre se constata esse efeito no teste de sanidade de sementes, onde não se observa controle significativo de $F$. moniliforme (Moraes et al., 1998). Existe a hipótese de que a luz diminui a eficiência do fludioxonil, o que explicaria os resultados obtidos através do método do papel de filtro, onde as sementes são incubadas sob luz branca fluorescente alternada ( $12 \mathrm{~h}$ de luz/12 h de escuro). Munkvold \& O'Mara (2002) testando efeito de fludioxonil no controle de espécies de Fusarium, utilizaram incubação no escuro.

Os objetivos deste trabalho foram verificar o efeito da luz sobre o crescimento micelial de $F$. moniliforme em meio de cultura contendo fungicidas, selecionar o melhor regime luminoso para se detectar $F$. moniliforme em sementes de milho tratadas com fungicidas e a maneira mais adequada de se proceder a essa avaliação, avaliar o efeito desses fungicidas no controle do patógeno e sobre a qualidade fisiológica das sementes.

\section{MATERIALEMÉTODOS}

Os experimentos foram desenvolvidos no Laboratório de Patologia de Sementes e em casa de vegetação do Departamento de Entomologia, Fitopatologia e Zoologia Agrícola - Setor de Fitopatologia, da Escola Superior de Agricultura “Luiz de Queiroz”/USP, nos anos de 2001 e 2002.

Foram utilizadas duas amostras de sementes de milho caracterizadas como: amostra 1 (alto vigor) - sementes com $88 \%$ de plântulas normais na primeira contagem do teste de germinação, 12,6 de índice de velocidade de emergência e 95\% de emergência em casa de vegetação; amostra 2 (baixo vigor) sementes com $57 \%$ de plântulas normais na primeira contagem do teste de germinação, 6,0 de índice de velocidade de emergência e $75 \%$ de emergência em casa de vegetação.

\section{Efeito da luz e de fungicidas no desenvolvimento de Fusarium moniliforme em sementes de milho e em meio de cultura}

Neste experimento utilizaram-se sementes da amostra 1, que foram tratadas com os fungicidas e suas doses correspondentes (Tabela 1).

O efeito da luz na detecção de $F$. moniliforme foi avaliado pelo método do papel de filtro com congelamento (Lucca Filho, 1987; Brasil, 1992), modificando-se as condições de luz. Foram distribuídas dez sementes sobre três folhas de papel de filtro umedecidas com água destilada, em placas de Petri de plástico de $9 \mathrm{~cm}$ de diâmetro. Estas placas foram incubadas por $24 \mathrm{~h}$ a $20 \pm 2{ }^{\circ} \mathrm{C}$ sob luz branca fluorescente alternada ( $12 \mathrm{~h}$ de luz $/ 12 \mathrm{~h}$ de escuro), luz próxima da ultra-violeta (NUV), também alternada, e escuro contínuo. A seguir foram levadas para congelador a $-18{ }^{\circ} \mathrm{C}$, durante $24 \mathrm{~h}$, retornando à câmara de incubação por mais cinco dias, sob as mesmas condições. Após esse período as sementes foram analisadas sob microscópio estereoscópico, avaliando-se a incidência (número de sementes) e severidade (área da semente coberta pela colônia) de $F$. moniliforme, com o objetivo de verificar se o modo de avaliação proporcionaria resultados diferentes. A avaliação da severidade consistiu em se dar notas de 0 a $10(0=$ semente sem crescimento de $F$. moniliforme, $1=0-10 \%$ da área da semente coberta com crescimento do fungo, $2=10-20 \%, 3=20-30 \%, 4=$ $30-40 \%, 5=40-50 \%, 6=50-60 \%, 7=60-70 \%, 8=70-80 \%, 9=80-$ $90 \%$ e $10=$ área coberta $>90 \%$ ), estabelecidas pelos autores.

O delineamento estatístico utilizado foi o inteiramente casualizado, esquema fatorial (três luz x oito fungicidas), com quatro repetições de 50 sementes cada. As comparações das médias foram feitas pelo teste de Tukey ao nível de 5\% de probabilidade.

O desenvolvimento de colônias de $F$. moniliforme em meio de cultura com fungicidas foi determinado com isolado do fungo obtido de sementes de milho. Para a produção do inóculo, discos de micélio foram transferidos para o centro de placas de Petri contendo meio de batata-dextrose-ágar (BDA). As placas foram colocadas em câmara de incubação sob temperatura de $20 \pm 2{ }^{\circ} \mathrm{C}$ e luz branca fluorescente ( $12 \mathrm{~h}$ de luz/ $12 \mathrm{~h}$ de escuro), durante sete dias.

TABELA 1 - Produtos e doses utilizados para o tratamento de sementes de milho (Zea mays) portadoras de Fusarium moniliforme

\begin{tabular}{llccl}
\hline \hline Nome Técnico & Nome Comercial & $\begin{array}{c}\text { Dose do i.a./100kg de } \\
\text { sementes }\end{array}$ & $\begin{array}{c}\text { Dose do p.c./100 kg de } \\
\text { sementes }\end{array}$ & Formulação \\
\hline Fludioxonil + metalaxil-m & Maxim XL 035 FS & $2,5 \mathrm{~g}+1,0 \mathrm{~g}$ & $100 \mathrm{ml}$ & SC \\
Fludioxonil + metalaxil-m & Apron Maxim RTA & $2,5 \mathrm{~g}+3,8 \mathrm{~g}$ & $330 \mathrm{ml}$ & Suspensão pronta para aplicar \\
Fludioxonil + metalaxil-m & Apron Maxim & $2,5 \mathrm{~g}+3,8 \mathrm{~g}$ & $25,7 \mathrm{ml}$ & SC \\
Difenoconazole & Spectro & $4,95 \mathrm{~g}$ & $33 \mathrm{ml}$ & SC \\
Acibenzolar-S-metílico & Bion 500 WG & $2,5 \mathrm{~g}$ & $5,0 \mathrm{~g}$ & Grânulo dispersível em água \\
Acibenzolar-S-metílico & Bion 500 WG & $5,0 \mathrm{~g}$ & $10,0 \mathrm{~g}$ & Grânulo dispersível em água \\
Captan + tiabendazole & Captan 750+Tecto SC & $75 \mathrm{~g}+18,0 \mathrm{~g}$ & $100 \mathrm{~g}+37,2 \mathrm{ml}$ & PS + SC \\
\hline
\end{tabular}


Para o preparo do substrato, cada fungicida foi adicionado ao meio de BDA, segundo técnica de Edgington $e t$ al. (1971), modificada (Menten et al., 1976). Os fungicidas avaliados foram diluídos, isoladamente, em $10 \mathrm{ml}$ de água destilada e esterilizada, obtendo-se assim a suspensão para a concentração de $100 \mu \mathrm{g} / \mathrm{ml}$ no meio. A partir desta, fizeram-se duas diluições em série, obtendo-se suspensões para as concentrações de 10 e $1 \mu \mathrm{g} / \mathrm{ml}$. Foram retirados $1 \mathrm{ml}$ de cada suspensão e colocados em $100 \mathrm{ml}$ de meio fundente $\left(45-47^{\circ} \mathrm{C}\right)$, obtendose meio de cultura com concentrações de 100,10 e $1 \mu \mathrm{g} / \mathrm{ml}$.

Discos de micélio de $5 \mathrm{~mm}$ de diâmetro, em crescimento ativo em BDA, foram transferidos para o centro das placas de Petri contendo BDA + fungicidas. A testemunha consistiu em BDA sem fungicida. A incubação foi efetuada a $20 \pm 2{ }^{\circ} \mathrm{C}$ e regime de luz descrito anteriormente, até completar sete dias da instalação do teste, mesmo período utilizado no teste de sanidade de sementes.

O delineamento experimental foi inteiramente casualizado, esquema fatorial (três luz x oito fungicidas), com três repetições por tratamento. As comparações das médias foram feitas pelo teste de Tukey ao nível de 5\% de probabilidade.

\section{Efeito do tratamento de sementes de milho com fungicidas no controle de Fusarium moniliforme e na qualidade fisiológica}

As duas amostras de sementes de milho descritas anteriormente, foram tratadas com os fungicidas e doses descritos (Tabela 1). Aplicou-se a calda em volume correspondente a $0,5 \%$ do peso das sementes. Para avaliar o efeito do tratamento sobre o controle de $F$. moniliforme e na qualidade fisiológica das sementes, utilizaram-se os seguintes testes.

Sanidade: para este teste foi utilizado o método do papel de filtro com congelamento, descrito anteriormente, sendo que as placas ficaram incubadas sob luz branca fluorescente alternada ( $12 \mathrm{~h}$ de luz/ $12 \mathrm{~h}$ de escuro) e temperatura de $20 \pm 2{ }^{\circ} \mathrm{C}$.

Germinação: utilizou-se o método do rolo de germinação (Brasil, 1992) para avaliar o vigor e porcentagem de germinação. As avaliações foram efetuadas aos quatro e sete dias após a instalação do teste, obtendo-se o vigor na primeira contagem e a germinação na última.

\section{Velocidade e porcentagem de emergência de plântulas em casa} de vegetação: este teste consistiu em se distribuir 50 sementes a uma profundidade de $1,5 \mathrm{~cm}$, em cada caixa plástica de 43 × 30 x $11 \mathrm{~cm}$, contendo solo esterilizado. As caixas foram mantidas em casa de vegetação e, a partir da data do início da emergência, foi anotado, diariamente, o número de plântulas emergidas até que o processo se estabilizasse. Com esses dados obteve-se, segundo Marco Filho et al. (1987), o índice de vigor denominado velocidade de emergência, e a porcentagem de plântulas emergidas.

Teste de frio: este teste foi desenvolvido em casa de vegetação, segundo metodologia descrita por Barros et al. (1999). As sementes foram distribuídas em caixas plásticas de 43 × 30 x 11 $\mathrm{cm}$, contendo uma mistura de areia (2/3) e solo proveniente de área cultivada com milho (1/3) e cobertas com 2 a $3 \mathrm{~cm}$ da mistura. O solo foi irrigado até $70 \%$ da sua capacidade de campo. As caixas foram colocadas em câmara regulada a $10^{\circ} \mathrm{C}$, durante sete dias; findo este período foram levadas para casa de vegetação onde permaneceram por mais sete dias, quando se procedeu a contagem do número de plântulas normais emergidas.

Estes experimentos foram instalados segundo o delineamento estatístico inteiramente casualizado, com oito tratamentos e quatro repetições de 50 sementes cada. As médias foram comparadas pelo teste de Tukey a $5 \%$ de probabilidade.

\section{RESULTADOSE DISCUSSÃO}

\section{Efeito da luz e de fungicidas no desenvolvimento de Fusarium moniliforme em sementes de milho e em meio de cultura}

Os dados do teste de sanidade (Tabela 2) mostram que não houve diferença significativa para os tipos de luz ou interação entre luz e fungicida, indicando que a luz branca ou NUV não inativa o ingrediente ativo dos produtos. Entretanto, houve diferença entre tratamentos fungicidas. Os mais eficientes foram captan + tiabendazole e fludioxonil + metalaxilm (97,2 g + 147,86 g/l), proporcionando controle acima de $90 \%$ para a variável severidade.

Constatou-se alta correlação $(r=0,87)$ entre incidência e severidade utilizadas para avaliação do teste de sanidade, demonstrando que ambas podem ser utilizadas para avaliar a qualidade sanitária de sementes de milho tratadas. Porém, observando-se a porcentagem de controle oferecido pelos produtos, verifica-se que a severidade é mais sensível (Tabela 3). Enquanto a incidência mostrou um controle médio, nos três tipos de luminosidade, em torno de $38 \%$, a severidade ficou em torno de $63 \%$. Provavelmente, a alta correlação se deve ao fato que as duas variáveis mostram os mesmos fungicidas efetuando o controle de $F$. moniliforme, mas não de quanto é essa eficiência.

A comparação entre as variáveis de avaliação do teste de sanidade, incidência e severidade, indicou que a severidade é mais sensível, porém essa metodologia de avaliação não é fácil de ser aplicada. Além de ser subjetiva, torna o tempo de avaliação mais prolongado.

No teste in vitro (Tabela 4) foram observados efeitos significativos para luz, fungicidas e interação entre luz e fungicidas. Os resultados dos fungicidas com ingrediente ativo fludioxonil + metalaxil $(25 \mathrm{~g}+10 \mathrm{~g} / \mathrm{l})$ na concentração de 100 $\mu \mathrm{g} / \mathrm{ml}$, fludioxonil + metalaxil $(7,5 \mathrm{~g}+11,51 \mathrm{~g} / \mathrm{l})$ nas concentrações de 100 e $1 \mu \mathrm{g} / \mathrm{ml}$ e captan + tiabendazole na concentração de $10 \mu \mathrm{g} / \mathrm{ml}$, mostraram que o controle foi melhor quando a incubação foi feita no escuro. Porém, o tratamento com fludioxonil + metalaxil $(92,27 \mathrm{~g}+147,86 \mathrm{~g} / \mathrm{l})$ não mostrou esse efeito, pois a incubação sob luz branca não diferiu estatisticamente do escuro e sob luz NUV, a 10 e $1 \mu \mathrm{g} / \mathrm{ml}$, o controle foi melhor. $\mathrm{O}$ difenoconazole proporcionou controle de $F$. moniliforme acima de $90 \%$, seguido do captan + tiabendazole e demais, na mesma ordem observada no experimento anterior. 
Controle químico de Fusarium moniliforme em semente de milho: metodologia...

TABELA 2 - Incidência e severidade de Fusarium moniliforme em sementes de milho (Zea mays), tratadas com fungicidas e submetidas a incubação sob diferentes regimes luminosos, no método do papel de filtro com congelamento

\begin{tabular}{|c|c|c|c|c|c|c|}
\hline \multirow{2}{*}{ Tratamento } & \multicolumn{2}{|c|}{ Luz Branca } & \multicolumn{2}{|c|}{ Luz NUV } & \multicolumn{2}{|c|}{ Escuro Contínuo } \\
\hline & Incidência* & Severidade* & Incidência & Severidade & Incidência & Severidade \\
\hline Fludioxonil+metalaxil-m ${ }^{1}$ & $60,0 \quad \mathrm{c}^{* *}$ & $1,43 \mathrm{~cd}$ & $51,0 \quad \mathrm{c}$ & $1,31 \mathrm{~cd}$ & 59,0 bc & $1,33 \mathrm{~cd}$ \\
\hline Fludioxonil + metalaxil-m ${ }^{2}$ & 76,0 bc & 2,21 & 82,0 b & 2,37 & $82,0 \mathrm{ab}$ & 2,18 \\
\hline Fludioxonil + metalaxil-m ${ }^{3}$ & $29,0 \quad d$ & 0,62 & $26,0 \quad d$ & 0,46 & $17,0 \quad \mathrm{~d}$ & 0,39 \\
\hline Difenoconazole & $56,0 \quad \mathrm{c}$ & $1,29 \mathrm{~cd}$ & 50,0 & $1,08 \mathrm{~cd}$ & $54,0 \quad \mathrm{c}$ & $1,18 \mathrm{~cd}$ \\
\hline Acibenzolar-S-Metílico(5) & 85,0 b & $4,82 \mathrm{~b}$ & $75,0 \mathrm{~b}$ & $5,17 \mathrm{~b}$ & $80,0 \mathrm{ab}$ & $4,71 \mathrm{~b}$ \\
\hline Acibenzolar-S-Metílico(10) & 85,0 b & $4,84 \mathrm{~b}$ & 78,0 b & $5,03 \mathrm{~b}$ & 72,0 bc & $4,90 \mathrm{~b}$ \\
\hline Captan+tiabendazole & 0,1 & 0,01 & 0,0 & $0,00 \quad \mathrm{~d}$ & $0,1 \quad \mathrm{e}$ & $0,01 \quad \mathrm{~d}$ \\
\hline Testemunha & $99,0 \mathrm{a}$ & $8,37 \mathrm{a}$ & $97,0 \mathrm{a}$ & $8,09 \mathrm{a}$ & $95,0 \mathrm{a}$ & $7,33 \mathrm{a}$ \\
\hline Média & 61,1 & 2,98 & 56,1 & 2,94 & 56,0 & 2,75 \\
\hline C.V. & $10,7 \%$ & $15,0 \%$ & $10,0 \%$ & $24,3 \%$ & $13,7 \%$ & 28,4 \\
\hline
\end{tabular}

1 - Suspensão concentrada de $25 \mathrm{~g}$ de fludioxonil $+10 \mathrm{~g}$ de metalaxil-m/l

2 - Solução pronta para aplicar (RTA) de 7,57 g de fludioxonil $+11,51 \mathrm{~g}$ de metalaxil-m/l

3 - Suspensão concentrada de $97,27 \mathrm{~g}$ de fludioxonil $+147,86 \mathrm{~g}$ de metalaxil-m/1

* Incidência: porcentagem de sementes com o fungo Severidade: notas de 0 a 10

** Médias seguidas pela mesma letra não diferem entre si, a 5\% de probabilidade, pelo teste de Tukey.

Não houve diferença significativa entre as luzes para as duas variáveis

TABELA 3 - Porcentagem de controle de Fusarium moniliforme oferecido pelo tratamento de sementes de milho (Zea mays) da amostra 1, em cada regime luminoso e variável utilizada para avaliação

\begin{tabular}{|c|c|c|c|c|c|c|}
\hline \multirow{2}{*}{ Tratamento } & \multicolumn{2}{|c|}{ Luz Branca Fluorescente } & \multicolumn{2}{|c|}{ Luz NUV } & \multicolumn{2}{|c|}{ Escuro Contínuo } \\
\hline & Incidência* & Severidade* & Incidência & Severidade & Incidência & Severidade \\
\hline Fludioxonil+metalaxil-m ${ }^{1}$ & 39 & 82 & 47 & 84 & 38 & 82 \\
\hline Fludioxonil+metalaxil-m ${ }^{2}$ & 23 & 74 & 15 & 71 & 14 & 70 \\
\hline Fludioxonil+metalaxil-m ${ }^{3}$ & 70 & 92 & 73 & 94 & 82 & 95 \\
\hline Difenoconazole & 43 & 84 & 48 & 87 & 43 & 84 \\
\hline Acibenzolar-S-Metílico(5) & 14 & 42 & 23 & 36 & 16 & 36 \\
\hline Acibenzolar-S-Metílico(10) & 14 & 42 & 20 & 38 & 24 & 33 \\
\hline Captan+tiabendazole & 99,9 & 99,9 & 100 & 100 & 99,9 & 99,9 \\
\hline Média & 37,9 & 64,5 & 40,8 & 63,8 & 39,6 & 62,5 \\
\hline
\end{tabular}

1 - Suspensão concentrada de $25 \mathrm{~g}$ de fludioxonil $+10 \mathrm{~g}$ de metalaxil-m/1

2 - Solução pronta para aplicar (RTA) de $7,57 \mathrm{~g}$ de fludioxonil + 11,51 g de metalaxil-m/1

3 - Suspensão concentrada de $97,27 \mathrm{~g}$ de fludioxonil + 147,86 g de metalaxil-m/l

* Incidência: porcentagem de sementes com o fungo Severidade: notas de 0 a 10

O acibenzolar-S-metílico não controlou o desenvolvimento do fungo, mostrando um crescimento maior do que a testemunha nas concentrações de 10 e $1 \mu \mathrm{g} / \mathrm{ml}$, podendo esse fato ser explicado por ser um produto que atua como indutor de resistência da planta (Araújo et al., 2002; Azevedo \& Arruda, 2002) e não diretamente sobre o fungo.

Esses resultados indicam que, apesar de não se ter constatado interação entre os fatores luz e fungicidas, no teste de sanidade, a luz pode influenciar o desempenho de determinados produtos no controle de F. moniliforme. Munkvold \& O'Mara (2002) utilizaram incubação em escuro contínuo para testar o efeito de fludioxonil no controle de espécies de Fusarium isolados da cultura do milho, constatando seu efeito positivo.

Efeito do tratamento de sementes de milho com fungicidas no controle de Fusarium moniliforme e na qualidade fisiológica

De acordo com o resultado do controle de $F$. moniliforme sobre a qualidade fisiológica das sementes (Tabelas 5 e 6), não se constatou diferença estatística entre os tratamentos para as variáveis germinação e emergência em casa de vegetação, nas sementes com alto vigor. A diferença observada na primeira contagem do teste de germinação mostrou um atraso no desenvolvimento das plântulas em sementes tratadas com acibenzolar-S-metílico, na dose de $5 \mathrm{~g}$ do pc/100 kg de sementes, diferindo da testemunha; no entanto, houve recuperação das plântulas na germinação final. $\mathrm{O}$ resultado de emergência em casa de vegetação mostrou menor porcentagem no tratamento com fludioxonil + metalaxil-m (25 + $10 \mathrm{~g} \mathrm{e} 7,57+11,51 \mathrm{~g} / \mathrm{l}$ ), porém sem diferir da testemunha. Não foi constatada alta correlação entre as variáveis incidência e primeira contagem do teste de germinação $(r=0,09)$, incidência e emergência $(r=0,14)$, severidade e primeira contagem $(r=0,01)$ e severidade e emergência $(r=0,30)$.

Nas sementes com baixo vigor, o F. moniliforme, avaliado através da incidência, foi controlado com $90 \%$ de 
M.H.D. Moraes et al.

TABELA 4 - Diâmetro médio (cm) de colônias de Fusarium moniliforme crescendo em meio de cultura (BDA) contendo fungicidas em três concentrações, sob diferentes regimes luminosos

\begin{tabular}{|c|c|c|c|}
\hline Produto & Luz Branca & Luz NUV & Escuro Contínuo \\
\hline Fludioxonil+metaxil-m ${ }^{1} 100 \quad 1 / \mathrm{ml}$ & $3,3 \quad$ h $A^{*}$ & $2,6 \quad$ fg $\mathrm{AB}^{*}$ & $1,9 \quad$ fg $\quad$ B \\
\hline Fludioxonil+metaxil-m ${ }^{1} 10 \quad$ 1/ml & fgh $A$ & $4,0 \quad$ def $A$ & $4,1 \quad \mathrm{de}$ \\
\hline Fludioxonil+metaxil-m ${ }^{1} 1 \quad 1 / \mathrm{ml}$ & efg A & 4,7 cde & 5,3 bcd \\
\hline Fludioxonil+metaxil-m ${ }^{2} 100 \quad 1 / \mathrm{ml}$ & 5,4 cdef $A$ & $5,1 \quad \mathrm{~cd}$ & 4,3 de \\
\hline Fludioxonil+metaxil-m² $10 \quad \mathrm{l} / \mathrm{ml}$ & gh $\mathrm{AB}$ & 3,5 ef & 4,5 cde \\
\hline Fludioxonil+metaxil-m ${ }^{2} 1 \quad 1 / \mathrm{ml}$ & efg A & 5,6 bc $\quad A$ & 3,2 \\
\hline Fludioxonil+metaxil-m ${ }^{3} 100 \quad 1 / \mathrm{ml}$ & i A & $\operatorname{gh} \mathrm{A}$ & gh A \\
\hline Fludioxonil+metaxil-m ${ }^{3} 10 \quad$ 1/ml & efg A & ef $B$ & cde A \\
\hline Fludioxonil+metaxil-m ${ }^{3} 1 \quad 1 / m l$ & defg A & 3,6 & 5,2 \\
\hline Difenoconazole $100 \quad 1 / \mathrm{ml}$ & j A & $\mathrm{h} \mathrm{A}$ & h A \\
\hline Difenoconazole $10 \quad$ 1/ml & $\mathrm{j} A$ & h A & $\operatorname{gh} \mathrm{A}$ \\
\hline Difenoconazole $1 \mathrm{l} / \mathrm{ml}$ & i A & g A & gh A \\
\hline Acibenzolar-S-metílico $100 \quad$ 1/ml & 5,8 bcde $\mathrm{A}$ & $5,9 \mathrm{bc}$ & $5,2 \mathrm{~cd}$ \\
\hline Acibenzolar-S-metílico $10 \quad$ 1/ml & $7,4 \mathrm{a}$ & $8,4 \mathrm{a}$ & $7,0 \mathrm{a}$ \\
\hline Acibenzolar-S-metílico 1 1/ml & $7,2 \mathrm{ab}$ & $6,9 \mathrm{~b}$ & $7,1 \mathrm{a}$ \\
\hline Captan+tiabendazole $100 \quad$ 1/ml & $\mathrm{j} A$ & $\mathrm{~h} A$ & h A \\
\hline Captan+tiabendazole $10 \quad 1 / \mathrm{ml}$ & gh A & gh $B$ & gh B \\
\hline Captan+tiabendazole 1 1/ml & $6,8 \mathrm{abc}$ & $6,8 \quad b$ & $6,0 \mathrm{abc}$ \\
\hline BDA sem fungicidas & 6,4 abcd & $6,9 \mathrm{~b}$ & $6,8 \mathrm{ab}$ \\
\hline Média & $4,05 \mathrm{~A}$ & $3,77 \mathrm{~B}$ & $3,66 \mathrm{~B}$ \\
\hline
\end{tabular}

TABELA 5 - Efeito do tratamento de sementes com fungicidas na incidência e severidade de Fusarium moniliforme e na qualidade fisiológica de sementes de milho (Zea mays) com alto vigor

\begin{tabular}{|c|c|c|c|c|c|c|c|}
\hline Tratamento & Incidência & Severidade & $\begin{array}{c}\text { Primeira } \\
\text { contagem }(\%)\end{array}$ & $\begin{array}{c}\% \\
\text { Germinação }\end{array}$ & $\begin{array}{c}\text { Velocidade de } \\
\text { Emergência }\end{array}$ & $\begin{array}{c}\% \\
\text { Emergência }\end{array}$ & $\begin{array}{l}\text { \% Emergência } \\
\text { (T. de Frio) }\end{array}$ \\
\hline Fludioxonil-metalaxil-m ${ }^{1}$ & $60,0 \quad \mathrm{c}^{*}$ & 1,43 & $83 \mathrm{~cd}$ & $95 \mathrm{~ns}$ & $10,6 \mathrm{~ns}$ & $86 \mathrm{~b}$ & $95 \mathrm{a}$ \\
\hline Fludioxonil-metalaxil- $\mathrm{m}^{2}$ & 76,0 bc & 2,21 & $91 \mathrm{abc}$ & 96 & 10,5 & $88 \mathrm{~b}$ & $97 \mathrm{a}$ \\
\hline Fludioxonil-metalaxil- $\mathrm{m}^{3}$ & $29,0 \quad d$ & 0,62 & $92 \mathrm{abc}$ & 96 & 12,6 & $96 \mathrm{ab}$ & $93 \mathrm{a}$ \\
\hline Difenoconazole & $56,0 \quad \mathrm{c}$ & $1,29 \mathrm{~cd}$ & $83 \mathrm{~cd}$ & 95 & 13,6 & $97 \mathrm{ab}$ & $52 \mathrm{~b}$ \\
\hline Acibenzolar-S-metílico(5) & 85,0 b & $4,82 \mathrm{~b}$ & $79 \mathrm{~d}$ & 98 & 14,0 & $100 \mathrm{a}$ & $25 \mathrm{bc}$ \\
\hline Acibenzolar-S-metílico (10) & 85,0 b & $4,84 \mathrm{~b}$ & $93 \mathrm{a}$ & 96 & 13,8 & $98 \mathrm{ab}$ & $19 \mathrm{c}$ \\
\hline Captan + tiabendazole & $0,1 \quad \mathrm{e}$ & 0,01 & 84 bcd & 98 & 12,8 & $95 \mathrm{ab}$ & $93 \mathrm{a}$ \\
\hline Testemunha & $99,0 \mathrm{a}$ & $8,37 \mathrm{a}$ & $88 \mathrm{abc}$ & 97 & 12,6 & $95 \mathrm{ab}$ & $35 \mathrm{bc}$ \\
\hline C.V. & $10,7 \%$ & $15,0 \%$ & $4,3 \%$ & 6,8 & 14,7 & $9,2 \%$ & $13,8 \%$ \\
\hline
\end{tabular}

1 - Suspensão concentrada de $25 \mathrm{~g}$ de fludioxonil $+10 \mathrm{~g}$ de metalaxil-m / 1

2 - Solução pronta para aplicar (RTA) de 7,57 g de fludioxonil + 11,51g de metalaxil-m / 1

3 - Suspensão concentrada de $97,27 \mathrm{~g}$ de fludioxonil + 147,86 g de metalaxil-m / 1

*Médias seguidas pela mesma letra, não diferem entre si, a $5 \%$ de probabilidade, pelo teste de Tukey.

eficiência pelo captan+tiabendazole. O fludioxonil + metalaxilm $(97,2 \mathrm{~g}+147,86 \mathrm{~g} / \mathrm{l})$ diferiu da testemunha, embora tenha apresentado alta incidência do patógeno. Os demais produtos não diferiram da testemunha. Apesar da alta correlação entre incidência e severidade $(\mathrm{r}=0,81)$, a variável severidade discriminou melhor o efeito dos fungicidas, segundo a qual o produto mais eficiente foi captan + tiabendazole, com $98 \%$ de controle, seguido do fludioxonil + metalaxil-m $(97,2 \mathrm{~g}+147,86 \mathrm{~g} / \mathrm{l} ; 25 \mathrm{~g}+$ $10 \mathrm{~g} / \mathrm{l} \mathrm{e} 7,57 \mathrm{~g}+11,51 \mathrm{~g} / \mathrm{l})$ e difenoconazole. Não se observou diferença estatística entre os tratamentos para os testes de qualidade fisiológica, com exceção do teste de frio (Tabela 6).

$\mathrm{O}$ teste de frio, que evidencia o efeito de Pythium sp. sobre as sementes e plântulas de milho, mostrou controle proporcionado pelos produtos a base de fludioxonil + metalaxil-m, 
Controle químico de Fusarium moniliforme em semente de milho: metodologia...

TABELA 6 - Efeito do tratamento de sementes com fungicidas na incidência e severidade de Fusarium moniliforme e na qualidade fisiológica de sementes de milho (Zea mays) com baixo vigor

\begin{tabular}{|c|c|c|c|c|c|c|c|}
\hline Tratamento & Incidência & Severidade & $\begin{array}{c}\text { Primeira } \\
\text { contagem }(\%)\end{array}$ & $\begin{array}{c}\% \\
\text { Germinação }\end{array}$ & $\begin{array}{l}\text { Velocidade de } \\
\text { Emergência }\end{array}$ & $\begin{array}{c}\% \\
\text { Emergência }\end{array}$ & $\begin{array}{c}\text { \% Emergência } \\
\text { (T. de Frio) }\end{array}$ \\
\hline Fludioxonil-metalaxil-m $^{1}$ & $100,0 \mathrm{a}^{* *}$ & $7,1 \quad \mathrm{c}$ & $62 \mathrm{~ns}$ & $76 \mathrm{~ns}$ & $8,0 \mathrm{~ns}$ & $79 \mathrm{~ns}$ & $70 \mathrm{a}$ \\
\hline Fludioxonil-metalaxil-m ${ }^{2}$ & $99,5 \mathrm{ab}$ & 7,9 bc & 47 & 68 & 7,0 & 79 & $75 \mathrm{a}$ \\
\hline Fludioxonil-metalaxil-m ${ }^{3}$ & $97,7 \quad b$ & $4,9 \quad \mathrm{~d}$ & 56 & 76 & 9,0 & 77 & $73 \mathrm{a}$ \\
\hline Difenoconazole & $99,9 \mathrm{ab}$ & $7,7 \quad \mathrm{c}$ & 54 & 72 & 5,5 & 84 & $18 \mathrm{~b}$ \\
\hline Acibenzolar-S-metílico (5) & $100,0 \mathrm{a}$ & $9,6 \mathrm{ab}$ & 55 & 76 & 5,2 & 76 & $2 \mathrm{c}$ \\
\hline Acibenzolar-S-metílico(10) & $100,0 \mathrm{a}$ & $9,6 \mathrm{ab}$ & 58 & 73 & 7,5 & 80 & $2 \mathrm{c}$ \\
\hline Captan+tiabendazole & $10,0 \quad \mathrm{c}$ & 0,2 & 61 & 79 & 6,0 & 82 & $70 \mathrm{a}$ \\
\hline Testemunha & $100,0 \mathrm{a}$ & $9,7 \mathrm{a}$ & 57 & 71 & 6,0 & 75 & $2 \mathrm{c}$ \\
\hline C. V. & $4,1 \%$ & $4,9 \%$ & $7,8 \%$ & $7,8 \%$ & $31,0 \%$ & $7,3 \%$ & $17,1 \%$ \\
\hline
\end{tabular}

1 - Suspensão concentrada de $25 \mathrm{~g}$ de fludioxonil $+10 \mathrm{~g}$ de metalaxil-m / 1

2 - Solução pronta para aplicar (RTA) de 7,57 g de fludioxonil + 11,51 g de metalaxil-m / 1

3 - Suspensão concentrada de 97,27 g de fludioxonil + 147,86 g de metalaxil-m / 1

*Médias seguidas pela mesma letra, não diferem entre si, a $5 \%$ de probabilidade, pelo teste de Tukey

nas três concentrações, e de captan + tiabendazole, elevando a porcentagem de emergência de $35 \%$ (testemunha) para $93 \%$ ou mais, na amostra 2, e de $2 \%$ (testemunha) para $70 \%$ ou mais. Esse resultado era esperado, pois captan e metalaxil são produtos recomendados para controle desse patógeno, e está de acordo com outros trabalhos realizados (Casa et al., 1995; Reis et al., 1995; Von Pinho et al., 1995; Moraes et al., 1998).

Os resultados obtidos com esse experimento levam a constatar que a qualidade fisiológica de sementes de milho não é afetada pela presença de Fusarium moniliforme, concordando com resultados obtidos por diversos autores (Bedendo, 1978; Von Pinho et al., 1995; Moraes et al., $1998 \mathrm{e}$ Pinto, 2000), provavelmente porque as amostras utilizadas neste experimento apresentavam alto e baixo vigor. Trabalhos realizados têm demonstrado que sementes com alto vigor não respondem ao tratamento com fungicidas e aquelas de baixo vigor são praticamente insensíveis. Apenas as sementes de médio vigor respondem ao tratamento (Menten, 1991b; Von Pinho et al., 1995 e Pinto, 1996).

\section{AGRADECIMENTOS}

Os autores agradecem o apoio financeiro da Syngenta Proteção de Cultivos Ltda.

\section{REFERÊNCIAS BIBLIOGRÁFICAS}

AZEVEDO, L.A.S. \& ARRUDA, J.J.A. Resposta de quatro cultivares de tomate a aplicações de acibenzolar-s-metil. Fitopatologia Brasileira 27:S54. 2002. (Resumo).

ARAUJO, J.S.P., OLIVEIRA, B.C., GONÇALVES, K.S., PORTO, C.M., BARBOSA N.P.A.S. \& LUSQUINOS, H.S. Resistência a murcha bacteriana em tomateiro, induzida pelo acibenzolar-s-methil. Fitopatologia Brasileira 27:S54. 2002. (Resumo).

BACON, C.W., HINTON. D.M. \& RICHARDSON, M.D. A corn seedling assay for resistance to Fusarium moniliforme. Plant Disease 78:302-305. 1994.
BARROS, A.S.R., DIAS, M.C.L.L., CÍCERO, S.M. \& KRZYZANOWSKI, F.C. Testes de Frio. In: Krzyzanowiski, F.C., Vieira, R.D. \& França Neto, J.B. (Eds.) Vigor de Sementes:conceitos e testes. Londrina. ABRATES. 1999. pp. 1-13

BEDENDO, I.P. Metodologia para detecção de Fusarium moniliforme Sheld. e sua ocorrência em sementes de milho (Zea mays L.) produzidas no estado de São Paulo. (Tese de Mestrado) Piracicaba. Escola Superior de Agricultura “Luiz de Queiroz”, Universidade de São Paulo. 1978.

BRASIL, Ministério da Agricultura e Reforma Agrária. Regras para Análise de Sementes. Brasília. 1992.

CARVALHO, M.L.M. Refrigeração e qualidade de sementes de milho armazenadas em pilhas com diferentes embalagens. (Dissertação de Doutorado). Piracicaba. Escola Superior de Agricultura "Luiz de Queiroz”, Universidade de São Paulo. 1992.

CASA, R.T., REIS, E.M., MEDEIROS, C.A. \& MOURA, F.B. Efeito do tratamento de sementes de milho com fungicidas, na proteção de fungos do solo, no Rio Grande do Sul. Fitopatologia Brasileira 20:633637. 1995.

EDGINGTON, L.V., KHEN, K.L. \& BARRON, G.L. Fungitoxic spectrum of benzimidazole compounds. Phytopathology 61:42-44. 1971.

FUTRELL, M.C. \& KILGOORE, M. Poor stands of corn and reduction of root growth caused by Fusarium moniliforme. Plant Disease Reporter 53:213-215. 1969.

GOULART, A.C.P. \& FIALHO, W.F. B. Tratamento de sementes de milho com fungicidas para o controle de patógenos. Summa Phytopathologica 27:414-420. 2001.

LUCCA FILHO O.A. Metodologia dos testes de sanidade de sementes. In: Soave, J. \& Wetzel, M.M.S. (Eds.) Patologia de Sementes. Campinas. Fundação Cargill. 1987. pp.276-298.

MACHADO, J.C. Patologia de Sementes: fundamentos e aplicações. Lavras:ESAL/FAEPE, 1988.

MARCOS FILHO, J., CÍCERO, S.M., \& SILVA, W.R. Avaliação da qualidade fisiológica das sementes. Piracicaba. FEALQ. 1987.

MENTEN, J.O.M. Prejuízos causados por patógenos associados às sementes. In: Menten, J.O.M. (Ed.) Patógenos em sementes: detecção, danos e controle químico. Piracicaba ESALQ/FEALQ. 1991a. pp.115136. 
MENTEN, J.O.M. Importância do tratamento de sementes. In: Menten, J.O.M. (Ed.) Patógenos em sementes:detecção, danos e controle químico. Piracicaba. ESALQ/FEALQ. 1991b. pp.203-224.

MENTEN, J.O.M., MACHADO, C.C., MINUSSI, E., CASTRO, C. \& KIMATI, H. Efeito de alguns fungicidas no crescimento micelial de Macrophomina phaseolina (tass.) Goid. in vitro. Fitopatologia Brasileira 1:57-64. 1976.

MORAES, M.H.D., ALMEIDA, R.R., SOUZA, L., MENTEN, J.O.M. \& CASTRO, R.M. Avaliação do desempenho de sementes de milho tratadas com fungicidas. Summa Phytopathologica 24:79. 1998. (Resumo)

MUNKVOLD, G.P. \& O'MARA, J.K. Laboratory and growth chamber evaluation of fungicidal seed treatments for maize seedling blight caused by Fusarium species. Plant Disease 86:143-150. 2002.

PEREIRA, O.A.P. Doenças do milho. In: Kimati, H. et al. (Eds.) Manual de Fitopatologia v. 2. São Paulo. Agronômica Ceres. 1995. pp.538-555.

PINTO, N.F.J.A. Tratamento de sementes com fungicidas. In: EMBRAPA Centro Nacional de Pesquisa de Milho e Sorgo. Sete Lagoas: EMBRAPA-CNPMS, (Circular Técnica) 1993.

PINTO, N.F.J.A. Tratamento fungicida de sementes de milho. In:
Soave, J., Oliveira, M.R.M. \& Menten, J.O.M. (Eds.) Tratamento químico de sementes. Anais, $4^{\circ}$ Simpósio Brasileiro de Patologia de Sementes, Gramado, RS, 1996. pp.52-57.

PINTO, N.F.J.A. Viabilidade de sementes de milho tratadas com fungicidas e armazenadas em condições ambientais. Summa Phytopathologica 26:47-52. 2000.

PINTO, N.F.J.A., MENTEN, J.O.M., LASCA, C.C., PEREIRA, O.P., MORAES, M.H.D. \& PEREIRA, H.S. Seleção de fungicidas para o tratamento de sementes de milho. Resumos, Congresso Nacional de Milho e Sorgo, Porto Alegre, RS, 1992. p.98.

REIS, A.C., REIS, E.M., CASA, R.T. \& FORCELINI, C.A. Erradicação dos fungos patogênicos associados a sementes de milho e proteção contra Pythium sp. presente no solo pelo tratamento com fungicidas. Fitopatologia Brasileira 20:585-590. 1995.

TANAKA, M.A.S. \& BALMER, E. Efeito de temperatura e dos microorganismos associados ao tombamento na germinação de sementes de milho (Zea mays L.) Fitopatologia Brasileira 5:87-93. 1980.

VON PINHO, E.V.R., CAVARIANI, C., ALEXANDRE, A.D., MENTEN, J.O.M. \& MORAES, M.H.D. Efeitos do tratamento fungicida sobre a qualidade sanitária e fisiológica de sementes de milho (Zea mays L.). Revista Brasileira de Sementes 17:23-28. 1995 